\title{
Outcomes among Patients Treated with Renal Replacement Therapy during Extracorporeal Membrane Oxygenation: A Single-Center Retrospective Study
}

\author{
David N. Dado ${ }^{a}$ e Craig R. Ainsworth ${ }^{f}$ Sarah B. Thomas ${ }^{b}$ Benjamin Huang ${ }^{a}$ \\ Lydia C. Piper $^{\mathrm{b}}$ Valerie G. Sams ${ }^{\mathrm{b}}$ Andriy Batchinskyc, d Benjamin D. Morrow ${ }^{\mathrm{a}, \mathrm{e}}$ \\ Anthony P. Basel ${ }^{f}$ Robert J. Walter ${ }^{a}$ e Phillip E. Mason ${ }^{b}$ Kevin K. Chung ${ }^{e}$ \\ a Department of Medicine, San Antonio Military Medical Center, San Antonio, TX, USA; ${ }^{\circ}$ Department of Surgery and \\ Trauma, San Antonio Military Medical Center, San Antonio, TX, USA; 'The Geneva Foundation, Tacoma, WA, USA;

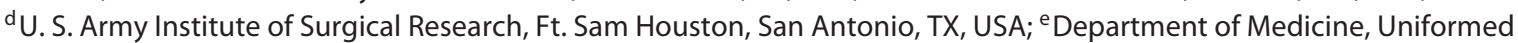 \\ Services University, Bethesda, MD, USA; ${ }^{f}$ Burn Center, U. S. Army Institute of Surgical Research, San Antonio, TX, USA
}

\section{Keywords}

Extracorporeal membrane oxygenation · Extracorporeal life support · Acute kidney injury · Continuous renal replacement therapy · Acute respiratory distress syndrome

\footnotetext{
Abstract

Background: Extracorporeal membrane oxygenation (ECMO) and continuous renal replacement therapy (CRRT) are modalities used in critically ill patients suffering organ failure and metabolic derangements. Although the effects of CRRT have been extensively studied, the impact of simultaneous CRRT and ECMO is less well described. The purpose of this study is to evaluate the incidence and the impact of CRRT on outcomes of patients receiving ECMO. Methods: A single center, retrospective chart review was conducted for patients receiving ECMO therapy over a 6-year period. Patients who underwent combined ECMO and CRRT were compared to those who underwent ECMO alone. Intergroup statistical comparisons were performed using Wilcoxon/ Kruskal-Wallis and chi-square tests. Logistic regression was performed to identify independent risk factors for mortality.
}

Results: The demographic and clinical data of 92 patients who underwent ECMO at our center were reviewed including primary diagnosis, indications for and mode of ECMO support, illness severity, oxygenation index, vasopressor requirement, and presence of acute kidney injury. In those patients that required ECMO with CRRT, we reviewed urine output prior to initiation, modality used, prescribed dose, net fluid balance after $72 \mathrm{~h}$, requirement of renal replacement therapy (RRT) at discharge, and use of diuretics prior to RRT initiation. Our primary endpoint was survival to hospital discharge. During the study period, 48 patients required the combination of ECMO with CRRT. Twenty-nine of these patients survived to hospital discharge. Of the 29 survivors, 6 were dialysis dependent at hospital discharge. The mortality rate was $39.5 \%$ with combined ECMO/CRRT compared to $31.4 \%$ among those receiving ECMO alone ( $p=0.074)$. Of those receiving combined therapy, nonsurvivors were more likely to have a significantly positive net fluid balance at $72 \mathrm{~h}$ $(p=0.001)$. A multivariate linear regression analysis showed net positive fluid balance and increased age were independently associated with mortality. Conclusions: Use of CRRT is prevalent among patients undergoing ECMO, with over

\begin{tabular}{ll}
\hline KARGER & (c) 2019 The Author(s) \\
Published by S. Karger AG, Basel & Ther \\
karger@karger.com & Then article is licensed under the Creative Commons Attribution- \\
NonCommercial-NoDerivatives 4.0 International License (CC BY- \\
NC-ND) (http://www.karger.com/Services/OpenAccessLicense). \\
Usage and distribution for commercial purposes as well as any dis- \\
tribution of modified material requires written permission.
\end{tabular}

David N. Dado, DO

San Antonio Military Medical Center

3551 Roger Brooke Drive, JBSA-Fort Sam Houston

San Antonio, TX 78234 (USA)

E-Mail david.n.dado.mil@mail.mil 
$50 \%$ of our patient population receiving combination therapy. Fluid balance appears to be an important variable associated with outcomes in this cohort. Rates of renal recovery and overall survival were higher compared to previously published reports among those requiring combined ECMO/ CRRT.

(c) 2019 The Author(s)

Published by S. Karger AG, Basel

\section{Introduction}

Extracorporeal membrane oxygenation (ECMO) is a life-saving therapy being used more frequently in critically ill patients, allowing for removal of carbon dioxide while providing oxygenation and circulatory support [1, $2]$. Due to the underlying severity of illness, these patients are at high risk of developing acute kidney injury (AKI) as well as fluid overload [3-5]. Continuous renal replacement therapy (CRRT) is frequently used in critically ill patients with a survival benefit for many populations [6-9]. It should be no surprise that the $40-60 \%$ of patients on ECMO who developed AKI were placed on CRRT $[7,8]$. To date, most data evaluating combined therapy $(\mathrm{ECMO}+\mathrm{CRRT})$ stem from the pediatric literature.

Using the Extracorporeal Life Support Organization registry including nearly 10,000 neonates and children, Askenazi et al. [9] revealed a higher mortality in patients with AKI requiring CRRT versus patients with AKI alone. In 4 small, single-center studies looking at adult patients with AKI requiring combined therapy, the mortality rates were $60,78,80$, and $100 \%$, respectively $[5,7,10,11]$. In a larger, more recent single-center study; 63 among $135 \mathrm{pa}$ tients required combined ECMO and CRRT; however, mortality rates were similar among groups receiving ECMO without AKI, ECMO with AKI, and ECMO with AKI requiring CRRT [12].

According to a recent survey, providers reported that the primary indication for renal replacement therapy (RRT) during ECMO therapy is for either fluid overload prevention or active volume management in nearly $60 \%$ of cases [10]. In both adult and pediatric literature, fluid overload has been associated with mortality and prolonged ECMO duration, while a negative fluid balance leads to improved respiratory function and time to weaning ECMO [8, 13-16]. Additionally, pediatric studies have shown that combining ECMO and CRRT leads to a decrease in cumulative fluid balance compared to those receiving ECMO alone $[8,17,18]$. Data in the adult population remain sparse.
The decision to initiate RRT is not without risk. While 2 large ECMO center studies showed no incidence of endstage renal disease in the absence of primary renal disease among pediatric patients receiving combined ECMO and CRRT therapy over a 20 -year follow-up, outcomes in adult patients remain poorly defined [19-20]. The purpose of this study was to conduct a single-center retrospective review of adult patients receiving combined ECMO and CRRT. We hypothesized that a high number of patients receive concurrent ECMO and CRRT and that ECMO patients who receive CRRT have a higher mortality.

\section{Materials and Methods}

This study was approved by the Brooke Army Medical Center Institutional Review Board. This is a retrospective analysis of all adult patients admitted to the San Antonio Military Medical Center and the US Army Institute for Surgical Research Burn Center requiring ECMO with or without CRRT support between January 1, 2012, and July 31, 2018. In total, 104 patient encounters were found to be eligible for analysis; however, 12 patient encounters were subsequently excluded as these patients required only transport ECMO support or they failed to provide consent ( 9 and 3 patients, respectively). The remaining 92 patient encounters were included in the final analysis. Of note, 2 patients required ECMO support twice during their hospitalization at our facility.

The demographic and clinical data of these 92 encounters were reviewed to include age, gender, race, primary diagnosis, indications for and mode of ECMO support, illness severity, oxygenation index, vasopressor requirement, and AKI severity. Illness severity was calculated using the Simplified Acute Physiology Score and AKI severity was determined by Kidney Disease Improving Global Outcomes stage $[21,22]$. In those patients that required ECMO with CRRT support, we additionally reviewed urine output in the $24 \mathrm{~h}$ prior to RRT initiation, use of a diuretic prior to RRT initiation, CRRT modality utilized, prescribed CRRT dose, net fluid balance after $72 \mathrm{~h}$ on CRRT, and requirement of RRT at discharge. Our primary endpoint was survival to hospital discharge. All data were obtained by manual chart review.

At our institution, ECMO is performed most commonly with the Cardiohelp system ${ }^{\mathrm{TM}}$ by Maquet (Rastatt, Germany). A small portion of patients underwent ECMO using the Maquet Rotaflow system $^{\mathrm{TM}}(2.9 \%)$ or a combination of the 2 systems $(0.96 \%)$. The decision to use venovenous or venoarterial ECMO was made at the discretion of the ECMO-trained intensivist based on the patient's underlying diagnosis and need for pulmonary or cardio-pulmonary support. The decision to initiate CRRT along with dosing, fluid removal, and replacement fluid selection was at the discretion of the intensivist (if credentialed in CRRT) or by a consulting nephrologist. CRRT was performed using the NxStage (Lawrence, MA, USA) or Prismaflex (Deerfield, IL, USA) machines. The vast majority of our patients received CRRT in line with their ECMO circuit (i.e., not through a separate, dedicated CRRT access). Standard premixed replacement fluids were prescribed as required by the patient's metabolic derangements. Anticoagulation was established with standard heparin protocol unless otherwise contrain- 
Table 1. Clinical characteristics of ECMO survivors vs. nonsurvivors

\begin{tabular}{|c|c|c|c|}
\hline Demographic/clinical variables & ECMO survivor $(n=61)$ & ECMO nonsurvivor $(n=29)$ & $p$ value \\
\hline Age, years* & $37.5(18-57)$ & $45.6(16-79)$ & 0.054 \\
\hline Gender, male & $38(62.3)$ & $25(89.3)$ & 0.006 \\
\hline \multicolumn{4}{|l|}{ Race } \\
\hline Caucasian & $13(39.4)$ & $8(44.4)$ & \multirow[t]{2}{*}{0.648} \\
\hline Hispanic & $13(39.4)$ & $7(21.2)$ & \\
\hline ECMO mode (VV) & $53(86.9)$ & $20(71.4)$ & 0.086 \\
\hline SAPS2* & $58.0(23-86)$ & $73.5(27-92)$ & 0.023 \\
\hline Oxygenation index* & $42.1(24.4-77.2)$ & $44.4(16.9-99.3)$ & 0.585 \\
\hline Vasopressor requirement & $21(77.8)$ & $14(73.7)$ & 0.749 \\
\hline \multicolumn{4}{|l|}{ ECMO indication } \\
\hline ARDS & $49(80.3)$ & $19(67.9)$ & 0.206 \\
\hline Cardiac failure & $7(11.5)$ & $4(12.5)$ & 0.711 \\
\hline $\begin{array}{l}\text { Data presented as } n(\%) \text { and } \\
* \text { Wilcoxon/KW test. } \\
\text { Comparison of characteristic } \\
\text { VV, venovenous; SAPS2, sim } \\
\text { QR, interquartile range. }\end{array}$ & \multicolumn{3}{|c|}{$\begin{array}{l}\text { Data presented as } n(\%) \text { and median (range/IQR). } \\
* \text { Wilcoxon/KW test. }\end{array}$} \\
\hline
\end{tabular}

dicated at the discretion of the ECMO attending. Kidney Disease Improving Global Outcomes definitions were used to grade AKI severity using data for the $24 \mathrm{~h}$ prior to ECMO cannulation.

Statistical analysis was performed using SPSS Statistical Software version 25 (IBM, Armonk, NY, USA). Intergroup statistical comparisons were performed using Wilcoxon/Kruskal-Wallis for the continuous variables (age, severity score, oxygenation index, urine output, CRRT duration, dose, and net fluid balance) and chisquare tests for the categorical data (gender, race, ECMO/CRRT modes/indications, vasopressor requirement, diuretic use, need for intermittent hemodialysis). Logistic regression was performed using age, gender, and net fluid balance as variables to identify independent risk factors for mortality. Statistical significance as defined at $p \leq 0.05$.

\section{Results}

During the study period, 90 patients received ECMO with $48(53.3 \%)$ requiring the combination of ECMO with CRRT. Of those patients receiving ECMO with CRRT, the mortality rate was $39.5 \%$. The mortality rate among those receiving ECMO alone was 31.4\%, which was not statistically different from those on combined therapy ( $p=0.074)$. Of the 29 survivors, $6(20.7 \%)$ were dialysis dependent at hospital discharge.

Of all patients receiving ECMO therapy, there was no difference between survivors and non-survivors with respect to ECMO mode, indication, vasopressor requirement, or oxygenation score as seen in Table 1. However, Simplified Acute Physiology Score severity score was higher in the nonsurvivor group, 73.5 vs. $58.0(p=0.23)$. Male gender was also associated with mortality for both ECMO patients and the ECMO/CRRT subset $(p=0.006$ and 0.001 , respectively).

Of those receiving combined ECMO/CRRT therapy, nonsurvivors were more likely to have a significantly positive net fluid balance at $72 \mathrm{~h}(p=0.001)$ as seen in Table 2 . There was no mortality difference in ECMO indication, AKI severity, CRRT indication, or CRRT initial dose for the combination ECMO/CRRT group. CVVH was the modality used in all cases. In a multivariate linear regression analysis, net fluid balance and age were found to be independently associated with mortality as seen in Table 3 .

\section{Discussion/Conclusion}

The intended purpose of this study was to define the incidence of concurrent CRRT with ECMO therapy and to determine the overall impact of this strategy on patient outcomes such as mortality and renal recovery. It was found that the majority of patients who underwent ECMO also received CRRT. This relationship is consistent with our study's hypothesis. The reciprocal risk of AKI and ARDS is a previously described phenomenon affecting many critically ill patients [3]. This association is important as it highlights the need for multisystem expertise and a multidisciplinary approach to the critically ill ECMO patient. This study also found that this combined 
Table 2. Clinical characteristics of ECMO/CRRT survivors vs. ECMO/RRT nonsurvivors

\begin{tabular}{|c|c|c|c|}
\hline Demographic/clinical variables & $\begin{array}{l}\text { ECMO/CRRT } \\
\text { survivor }(n=29)\end{array}$ & $\begin{array}{l}\text { ECMO/CRRT } \\
\text { nonsurvivor }(n=19)\end{array}$ & $p$ value \\
\hline Age, years* & $38.6(18$ to 63$)$ & 42.7 (16 to 79$)$ & 0.104 \\
\hline Gender, male & $16(55.2 \%)$ & $18(94.7)$ & 0.001 \\
\hline \multicolumn{4}{|l|}{ Race } \\
\hline Caucasian & $8(30.8)$ & $8(44.4)$ & \multirow[t]{2}{*}{0.586} \\
\hline Hispanic & $13(50.0)$ & $8(44.4)$ & \\
\hline ECMO mode (VV) & $23(79.3)$ & $13(68.4)$ & 0.398 \\
\hline SAPS2* $(n=27)$ & 66.5 (51 to 86$)$ & $75.0(27$ to 92$)$ & 0.288 \\
\hline Oxygenation index* $(n=21)$ & $44.1(20.1$ to 80.8$)$ & 40.7 (26.4 to 77.2$)$ & 0.823 \\
\hline Vasopressor requirement & $21(77.8)$ & $14(73.7)$ & 0.749 \\
\hline \multicolumn{4}{|l|}{ ECMO indication } \\
\hline ARDS & $23(79.3)$ & $19(67.9)$ & 0.398 \\
\hline Cardiac failure & $5(17.2)$ & $13(68.4)$ & 0.512 \\
\hline \multicolumn{3}{|l|}{ KDIGO stage AKI } & \multirow[t]{5}{*}{0.613} \\
\hline 0 & $9(31.0)$ & $3(15.7)$ & \\
\hline 1 & $3(10.3)$ & $2(10.5)$ & \\
\hline 2 & $6(20.6)$ & $3(15.7)$ & \\
\hline 3 & $11(37.9)$ & $10(52.6)^{\#}$ & \\
\hline UOP prior $24 \mathrm{~h}^{*}$ & $1,229(0$ to 4,715$)$ & $1,809(0$ to 5,488$)$ & 0.134 \\
\hline Diuretic use $(n=48)$ & $12(44.4)$ & $4(22.2)$ & 0.122 \\
\hline CRRT indication volume management & $24(82.7)$ & $14(73.7)$ & 0.122 \\
\hline Days requiring CRRT* & $10(1$ to 59$)$ & $8(1$ to 24$)$ & 0.642 \\
\hline Initial dose, $\mathrm{mL} / \mathrm{kg} / \mathrm{h}^{*}$ & 34.8 (11.8 to 75.3$)$ & $37.7(20.0$ to 71.4$)$ & 0.620 \\
\hline $72 \mathrm{~h}$ net fluid balance, $\mathrm{mL}(\mathrm{L})^{*}$ & $-3,353(-12.6$ to 10$)$ & $1,897(-3.6$ to 15.1$)$ & 0.001 \\
\hline $\begin{array}{l}\text { Data presented as } n(\%) \text { and median } \\
\text { * Wilcoxon/KW test. } \\
\text { \# One nonsurvivor was ESRD at base } \\
\text { Comparison of characteristics of ECl } \\
\text { VV, venovenous; SAPS2, simplified } \\
\text { RRT, renal replacement therapy; CRRT } \\
\text { Improving Global Outcomes; IQR, inter }\end{array}$ & $\begin{array}{l}\text { ange/IQR). } \\
\text { ne. } \\
\mathrm{O}+\text { CRRT patients by } \\
\text { ute physiology score; } \mathrm{E} \\
\text { continuous RRT; AKI, } \\
\text { uartile range. }\end{array}$ & $\begin{array}{l}\text { ality. } \\
\text {, extracorporeal memb } \\
\text { kidney injury; KDIG }\end{array}$ & $\begin{array}{l}\text { ygenation; } \\
\text { y Disease }\end{array}$ \\
\hline
\end{tabular}

Table 3. Multivariate logistic regression analysis for mortality

\begin{tabular}{lcccc}
\hline Clinical factor & OR & Lower 95\% & Upper 95\% & $p$ value \\
\hline Age, years* & 1.0671 & 1.008778 & 1.128794 & 0.0109 \\
Net fluid balance, dL* & 1.022739 & 1.006318 & 1.039428 & 0.0009 \\
Gender, male/female & 16.657854 & 1.4769763 & 187.87309 & 0.0229 \\
\hline
\end{tabular}

* OR per unit change in regressor.

Multivariate logistic regression analysis for mortality.

Tests and CIs on ORs are wald based.

therapy was associated with increased mortality compared with ECMO alone. Although this theme is consistent with previous literature, our mortality rates for combination ECMO/CRRT were considerably lower than published data, 39.5 vs. $60-100 \%$ [7, 8, 23, 24].
Several factors may account for the difference in survival rates between our patients and those previously reported. First, our patients that received CRRT may have less severe AKI at initiation of therapy. Of the patients in our series who required combined ECMO and CRRT, 
$41 \%$ of survivors were initiated on CRRT with no AKI or stage 1 AKI versus only $25 \%$ of nonsurvivors. Although our overall incidence was similar to the published rate of AKI for ECMO patients (71-81\%), it is difficult to compare these findings to the current literature as a breakdown of AKI severity is not available in those reports [2, $3,23,24]$. Whether the impact on survival is related to lower illness severity or early aggressive initiation of therapy is an intriguing and unanswered question.

Second, age and patient comorbidities likely impacted our overall survival. The median age in our survival group was 39 years compared to 43 years in the nonsurvival group. Although this difference was insignificant, multivariate logistic regression analysis revealed age to be a determinant for mortality $(p=0.01)$. Our institution is a military facility that cares for military members, beneficiaries and retirees. Because of this, our patient population as a whole is younger and with less comorbidities when compared with civilian hospitals. We do receive a fair number of civilian trauma and burn patients, accounting for roughly one-third of our registry. However, they are also classically a younger cohort of patients, but with significant injury similar to civilian facilities.

Lastly, the physicians and nurses who have developed and maintained our ECMO program are by and large the same physicians and nurses who have helped develop and maintain our CRRT program. There are multiple publications that demonstrate improved outcomes at centers who perform a high volume of complicated or specialized procedures $[25,26]$. Stemming from this, our intensive care program is a proponent of early and aggressive initiation of RRT. However, each patient is managed individually by a credentialed Intensivist or Nephrologist with CRRT rather than via a protocolized approach as many centers do. This is evident in the vast variations in dosing. This early integration of therapy, in combination with our program's experience and expertise, may contribute to our improved outcomes. However, it also potentially increases our selection bias with a less critically ill population undergoing combined ECMO/CRRT than at other institutions who may reserve combination therapy for sicker patients.

In our 48 patients who received combined ECMO and CRRT, a $3 \mathrm{~L}$ negative fluid balance in the first $72 \mathrm{~h}$ was independently associated with survival $(p=0.001)$. In contrast, those patients in the series who died had an average $1.8 \mathrm{~L}$ positive fluid balance in the first $72 \mathrm{~h}$. According to a recent multicenter survey of physicians performing ECMO regarding the combined use of RRT and ECMO, the most common reason for RRT initiation is volume management for fluid overload or fluid overload prevention [10]. Fluid overload is associated with increased mortality and prolonged ECMO duration $[8,13$, 14]. Addressing volume overload with fluid removal via ultrafiltrate is associated with improved respiratory function and time to weaning ECMO $[8,15,16]$. Peak fluid overload and fluid overload at ECMO initiation were both predictive of hospital mortality in children [27]. Several studies in neonates and children have shown that combining ECMO and RRT leads to less cumulative fluid overload than those receiving ECMO alone $[8,17,18]$. While there is sparse data among adult patients, higher fluid balance was consistently associated with poor survival in adults receiving venoarterial-ECMO [17]. The international ELSO guidelines recognize this and thus recommend to "return the extracellular fluid volume to normal (dry weight) and maintain it there" [2].

While this may appear to suggest that early and aggressive initiation of RRT to prevent hypervolemia may improve outcomes, a couple of caveats apply. We believe this represents only an association between negative fluid balance in the first $72 \mathrm{~h}$ and survival. Our patient population included medical, surgical, and traumatic etiologies prompting ECMO and/or CRRT therapy. The underlying mechanisms and physiology behind ARDS development in each of these populations may dictate different goals of treatment. For example, resuscitation after a devastating burn injury will differ considerably than fluid goals for patients presenting with cardiac failure. Those with reversible volume overload as a component of their ARDS were more likely to benefit from aggressive fluid removal and survive. On the other hand, those who were not volume overloaded upon initiation of ECMO may have had a less reversible form of lung pathology.

We are one of only a few studies in adults and pediatrics to report on the rates of renal recovery after combined ECMO and CRRT. Twenty percent of patients in our study who required combined therapy went on to require on-going renal support at hospital discharge. Two pediatric studies report long-term RRT requirements of 4 and $6 \%$ over 20 years of follow-up in the absence of primary renal disease $[19,20]$. One small study showed that among adult ECMO patients receiving CRRT, 3 out of 8 survivors (35\%) required ongoing renal support at discharge and 1-month follow-up [28]. We were unable to find any data on survival and renal outcomes beyond this in adult patients. This is an area that needs further investigation as the critical care community continues to increase its use of these advanced organ support modalities. 
There were several limitations of our study. First, it is a single-center study so equipment and capabilities as well as provider practice may vary significantly at different institutions. For instance, a small portion of patients underwent ECMO using the Maquet Rotaflow system ${ }^{\mathrm{TM}}$, but the standard of care in our institution is now the Cardiohelp system ${ }^{\mathrm{TM}}$ by Maquet. Our study was also retrospective so patients were not randomly assigned and therefore variations in treatment, namely, volume management, must be interpreted and applied with caution. We also did not have complete data on all patients prior to their arrival at our facility so some variables such as illness severity, vasopressor use, diuretic use, fluid and resuscitation status, and prior therapies were unknown and may have affected outcomes. Last, we practice in a military facility and many of our patients were civilians transferred from various parts of the region, as such we do not have long-term follow-up data beyond discharge for many of these patients. We have updated our patient database collection methods to have a greater emphasis on tracking patients beyond discharge to determine longterm outcomes.

The majority of patients on ECMO in our series went on to require CRRT. This is important information for aspiring hospitals to consider when discussing planning and staffing needs for new ECMO programs. Patients in our series who required CRRT in addition to ECMO had survival rates comparable to the survival rates published by the Extracorporeal Life Support Organization for patients requiring ECMO alone [23]. These survival rates are higher than previously published survival rates for patients on combined therapy.

The use of CRRT is prevalent among patients undergoing ECMO, with over $50 \%$ of our patient population receiving combination therapy. Univariate and multivariate predictors of outcome pointed to age, gender, and fluid balance as main predictors of survival. Fluid balance is a modifiable risk factor. Early and aggressive initiation of CRRT while on ECMO to target a negative flu- id balance is something that should be pursued and further prospective trials are needed to confirm these outcomes. Additional investigation is needed regarding long-term outcomes of patients requiring combined therapy.

\section{Acknowledgments}

The Geneva Foundation to include Brendan Beely (Research Coordinator), John Jones (Statistician), and Daniel Wendorff (Research Associate). James Lantry of Baltimore STC/CSTARS (Consultant).

\section{Statement of Ethics}

Regional Health Command-Central Institutional Review Board, Reference No. C.2017.152d. Approved August 25, 2017.

\section{Disclosure Statement}

The authors have no conflicts of interest to declare. The authors declare that they have no competing interests. The opinions or assertions contained herein are the private views of the authors and are not to be construed as official or as reflecting the views of the Department of the Army, Air Force or the Department of Defense.

\section{Funding Sources}

USAF/AFMS (59 MDW), Award\# FA8650-15-C-6692.

\section{Author Contributions}

D.N.D., C.R.A., S.B.T., and A.B. all assisted in compiling, analyzing, and interpreting patient data. Additionally, they wrote and revised the manuscript. B.H. and L.C.P. assisted in the compilation of the patient database. A.P.B., V.G.S., B.D.M., R.J.W.,P.E.M., and K.K.C. consented patients, offered project oversight, and assisted in concept proposal and manuscript revision. All authors read and approved the final manuscript.

\section{References}

1 Paden ML, Conrad SA, Rycus PT, Thiagarajan RR.; ELSO Registry. Extracorporeal life support organization registry report 2012. ASAIO J. 2013 May-Jun;59(3):202-10.

2 Extracorporeal Life Support Organization. ELSO Adult Respiratory Failure Guidelines, v1.4: 23, 2017. [Accessed August 10, 2018]. Available from: https://www.elso.org/Resources/Guidelines.aspx.
3 Clemens MS, Stewart IJ, Sosnov JA, Howard JT, Belenkiy SM, Sine CR, et al. Reciprocal Risk of Acute Kidney Injury and Acute Respiratory Distress Syndrome in Critically Ill Burn Patients. Crit Care Med. 2016 Oct; 44(10):e915-22.

4 Lin CY, Chen YC, Tsai FC, Tian YC, Jenq CC, Fang JT, et al. RIFLE classification is predictive of short-term prognosis in critically ill patients with acute renal failure supported by extracorporeal membrane oxygenation. Nephrol Dial Transplant. 2006 Oct;21(10):2867-73.

5 Yan X, Jia S, Meng X, Dong P, Jia M, Wan J, et al. Acute kidney injury in adult postcardiotomy patients with extracorporeal membrane oxygenation: evaluation of the RIFLE classification and the Acute Kidney Injury Network criteria. Eur JCardiothorac Surg. 2010 Feb;37(2):334-8. 
6 Chung KK, Juncos LA, Wolf SE, Mann EE, Renz EM, White CE, et al. Continuous renal replacement therapy improves survival in severely burned military casualties with acute kidney injury. J Trauma. 2008 Feb;64(2 Suppl):S179-85.

7 Kielstein JT, Heiden AM, Beutel G, Gottlieb J, Wiesner $\mathrm{O}$, Hafer $\mathrm{C}$, et al. Renal function and survival in 200 patients undergoing ECMO therapy. Nephrol Dial Transplant. 2013 Jan; 28(1):86-90.

8 Swaniker F, Kolla S, Moler F, Custer J, Grams $\mathrm{R}$, Barlett R, et al. Extracorporeal life support outcome for 128 pediatric patients with respiratory failure. J Pediatr Surg. 2000 Feb;35(2): 197-202.

9 Askenazi DJ, Selewski DT, Paden ML, Cooper DS, Bridges BC, Zappitelli M, et al. Renal replacement therapy in critically ill patients receiving extracorporeal membrane oxygenation. Clin J Am Soc Nephrol. 2012 Aug;7(8): 1328-36.

10 Fleming GM, Askenazi DJ, Bridges BC, Cooper DS, Paden ML, Selewski DT, et al. A multicenter international survey of renal supportive therapy during ECMO: the Kidney Intervention During Extracorporeal Membrane Oxygenation (KIDMO) group. ASAIO J. 2012 Jul-Aug;58(4):407-14.

11 Yap HJ, Chen YC, Fang JT, Huang CC. Combination of continuous renal replacement therapies (CRRT) and extracorporeal membrane oxygenation (ECMO) for advanced cardiac patients. Ren Fail. 2003 Mar;25(2): 183-93.

12 Antonucci E, Lamanna I, Fagnoul D, Vincent JL, De Backer D, Silvio Taccone F. The Impact of Renal Failure and Renal Replacement Therapy on Outcome During Extracorporeal Membrane Oxygenation Therapy. Artif Organs. 2016 Aug;40(8):746-54.

13 Selewski DT, Cornell TT, Lombel RM, Blatt NB, Han YY, Mottes T, et al. Weight-based determination of fluid overload status and mortality in pediatric intensive care unit patients requiring continuous renal replacement therapy. Intensive Care Med. 2011 Jul; 37(7):1166-73.

14 Blijdorp K, Cransberg K, Wildschut ED, Gischler SJ, Jan Houmes R, Wolff ED, et al. Haemofiltration in newborns treated with extracorporeal membrane oxygenation: a casecomparison study. Crit Care. 2009;13(2):R48.

15 Anderson HL 3rd, Coran AG, Drongowski RA, Ha HJ, Bartlett RH. Extracellular fluid and total body water changes in neonates undergoing extracorporeal membrane oxygenation. J Pediatr Surg. 1992 Aug;27(8): 1003-7.

16 Kelly RE Jr, Phillips JD, Foglia RP, Bjerke HS, Barcliff LT, Petrus L, et al. Pulmonary edema and fluid mobilization as determinants of the duration of ECMO support. J Pediatr Surg. 1991 Sep;26(9):1016-22.

17 Hoover NG, Heard M, Reid C, Wagoner S, Rogers K, Foland J, et al. Enhanced fluid management with continuous venovenous hemofiltration in pediatric respiratory failure patients receiving extracorporeal membrane oxygenation support. Intensive Care Med. 2008 Dec;34(12):2241-7.

18 Cavagnaro F, Kattan J, Godoy L, Gonzáles A, Vogel A, Rodríguez JI, et al. Continuous renal replacement therapy in neonates and young infants during extracorporeal membrane oxygenation. Int J Artif Organs. 2007 Mar;30(3): 220-6.

19 Meyer RJ, Brophy PD, Bunchman TE, Annich GM, Maxvold NJ, Mottes TA, et al. Survival and renal function in pediatric patients following extracorporeal life support with hemofiltration. Pediatr Crit Care Med. 2001 Jul; 2(3):238-42.

20 Paden ML, Warshaw BL, Heard ML, Fortenberry JD. Recovery of renal function and survival after continuous renal replacement ther- apy during extracorporeal membrane oxygenation. Pediatr Crit Care Med. 2011 Mar; 12(2):153-8.

21 Le Gall JR, Lemeshow S, Saulnier F. A new Simplified Acute Physiology Score (SAPS II) based on a European/North American multicenter study. JAMA. 1993 Dec;270(24):295763.

22 International Society of Nephrology. KDIGO Clinical Practice Guidelines for Acute Kidney Injury. Kidney Int. 2012;2:1-141.

23 Gadepalli SK, Selewski DT, Drongowski RA, Mychaliska GB. Acute kidney injury in congenital diaphragmatic hernia requiring extracorporeal life support: an insidious problem. J Pediatr Surg. 2011 Apr;46(4):630-5.

24 Smith AH, Hardison DC, Worden CR, Fleming GM, Taylor MB. Acute renal failure during extracorporeal support in the pediatric cardiac patient. ASAIO J. 2009 Jul-Aug;55(4): 412-6.

25 Kahn JM, Goss CH, Heagerty PJ, Kramer AA, O’Brien CR, Rubenfeld GD. Hospital volume and the outcomes of mechanical ventilation. N Engl J Med. 2006 Jul;355(1):41-50.

26 Nguyen YL, Wallace DJ, Yordanov Y, Trinquart L, Blomkvist J, Angus DC, et al. The Volume-Outcome Relationship in Critical Care: A Systematic Review and Meta-analysis. Chest. 2015 Jul;148(1):79-92.

27 Selewski DT, Askenazi DJ, Bridges BC, Cooper DS, Fleming GM, Paden ML, et al. The Impact of Fluid Overload on Outcomes in Children Treated With Extracorporeal Membrane Oxygenation: A Multicenter Retrospective Cohort Study. Pediatr Crit Care Med. 2017 Dec;18(12):1126-35.

28 Thajudeen B, Kamel M, Arumugam C, Ali SA, John SG, Meister EE, et al. Outcome of patients on combined extracorporeal membrane oxygenation and continuous renal replacement therapy: a retrospective study. Int J Artif Organs. 2015 Mar;38(3):133-7. 